\title{
A trajetória intelectual de Canguilhem
}

\author{
Carolina de Souza Noto | Universidade de São Paulo
}

Georges Canguilhem, Résistence, philosophie biologique et histoire des sciences 1940-1965 (Oeuvres Complètes, tome IV). Paris: Vrin, 2015.

Em janeiro de 1996, poucos meses após a morte de Georges Canguilhem (1904-1995), sua mulher, Simone Canguilhem, em uma carta a Jacques Bouveresse, ex-aluno e amigo próximo de Canguilhem, solicita que este cuide pessoalmente do porvir da obra de seu marido. Em 2003, depois da morte de Simone, esse pedido é reiterado pelos filhos de Canguilhem, Bernard e Francette, e em 2011, com Jacques Bouveresse na presidência da comissão editorial, temos a publicação do primeiro volume das Obras Completas de Georges Canguilhem pela renomada editora Vrin. Respeitando o desejo do próprio Canguilhem de que nenhum de seus escritos inéditos fosse publicado depois de sua morte, as Obras Completas consistem numa reunião exaustiva de todo tipo de produção que de uma maneira ou de outra foi tornada pública durante a vida do autor: aulas, conferências, entrevistas radiofônicas e televisivas, artigos em revistas e jornais, resenhas, cartas, livros etc.

O conjunto da obra está previsto para ser composto por 6 tomos. O tomo I, surgido em 2011, contém a produção de Canguilhem menos conhecida. Inclui escritos filosóficos e políticos que vão de 1926 a 1939, isto é, que vão desde seu período de normalien até o início da Segunda Guerra Mundial. Os tomos II e III, ainda não publicados, em contrapartida, serão compostos pelos textos já clássicos do autor. No tomo II, teremos as três teses: a de medicina, defendida em 1943, Essai sur quelques problèmes concernant 
le normal et le pathologique; a tese complementar de filosofia, de 1952, La connaissance de la vie; e a tese principal, publicada em 1955, La formation du concept de réflexe aux XVIIe siècle. Do tomo III fará parte o trabalho coletivo Du développement à l'évolution, publicado em 1962 na revista Thalès, e o livro Études d'histoire et de philosophie des sciences, que contém artigos e comunicações do fim da década de 50 e início da década de 6o, publicado em 1968. Seguindo a ordem cronológica da produção de Canguilhem, o tomo IV, publicado em meados de 2015, contém escritos que vão de 1940 a 1965. O tomo $\mathrm{V}$, ainda por vir, comportará os escritos de 1966 a 1995 e, por fim, no último tomo teremos a reunião de uma série de textos diversificados de Canguilhem (textos administrativos e "rapports d'agrégation"), assim como uma bibliografia crítica.

No que diz respeito ao tomo IV das Obras completas, é de se notar, como aponta Camille Limoges na introdução ao livro, que os textos de 1940-1965 são muito mais heterogêneos do que os de 1926-1939'; para Limoges, isso reflete a diversidade de acontecimentos vivenciados por Canguilhem nesse período: a guerra, a ocupação nazista, o regime de Vichy, a Resistência, as tarefas administrativas e políticas assumidas no período da Libertação, o início no Ensino Superior em Clermont-Ferrand, posto que foi ocupado por Jean Cavaillès (assassinado pela Gestapo), o cargo de Inspetor Geral de educação de filosofia para o segundo grau e, por fim, sua entrada na Sorbonne e no Institut d'Histoire des Sciences et des Techniques, em 1955, no lugar de Bachelard. Em contraposição a esse período de efervescência política e intelectual, os escritos reunidos no primeiro tomo, que se referem aos primeiros anos de vida intelectual de Canguilhem, são reflexo de

1 Cf. LIMOGES, C. "Introduction: Philosophie biologique, histoires des sciences et interventions philosophiques. Georges Canguilhem (1940-1965)". In: Georges Canguilhem: résistence, philosophie biologique et histoire des sciences (1940-1965). Oeuvres Complètes, t. IV. Paris: Vrin, 2015, p. 8. 
uma fase relativamente tranquila, em que Canguilhem conclui seus estudos na École Normale Supérieure, leciona em alguns liceus e trata, de maneira geral, de temas já conhecidos da filosofia de Alain: o pacifismo político e a primazia do juízo em relação à ação e à experiência em geral. Muitos dos textos reunidos no tomo I das Obras Completas foram originalmente publicados na revista Libres Propos, dirigida por Alain, o que deixa patente a proximidade entre os dois filósofos. Além disso, esse tomo agrega o interessantíssimo Traité de logique et de moral, que Canguilhem, ainda como professor do Liceu de Toulouse, publica em 1939 juntamente com Camille Planet, professor de filosofia do Liceu de Marseille. O texto deveria servir, conforme os próprios autores advertem, como "trabalho documentado útil" aos professores de filosofia do secundário; mais do que um manual de filosofia, o Traité deveria funcionar como um "exemplo" de reflexão filosófica ordenada, sistemática e coerente ${ }^{2}$. Os temas não fogem muito do que estava estabelecido pelo programa obrigatório ${ }^{3}$, afinal o livro consiste no material desenvolvido por Canguilhem e Planot ao longo dos anos de liceu. O caráter didático da obra, porém, não retira sua originalidade e, em se tratando de Canguilhem, revela algo de seu pensamento e de suas opções filosóficas. Nesse sentido, vale ressaltar que o tema da unificação da experiência por meio do juízo e da hierarquização dos valores é recorrente ao longo de toda a obra. Temas que marcam não só a influência da filosofia de Alain, mas o esboço de uma filosofia biológica ou filosofia da vida que já começara a ser delineada alguns anos antes, em 1937 e 1938, em textos mais conhecidos aos leitores de Canguilhem, como "Descartes et la technique" e "Activité et création".

E se é verdade que já no final da década de 30 é possível

2 Cf. CANGUILHEM, C. e PLANET, C. Traité de logique et morale. In: Georges Canguilhem, Oeuvres Complètes, t. I, p. 635 .

3 Na edição do tomo I das Obras Completas, temos acesso ao que seria o Programa de Ensino de Filosofia de 1923. Cf. Georges Canguilhem, Oeuvres Complètes, t. I, p. 627. 
encontrar traços de uma filosofia da vida que Canguilhem viria a desenvolver de maneira mais elaborada a partir da década de 40, também é digno de nota que é ainda antes do início da Segunda Guerra que o discípulo de Alain começa a repensar a postura política de seu mestre. Os editores das Obras Completas são unânimes a esse respeito: a transferência de Canguilhem para Toulouse, em 1936, é determinante para seu afastamento em relação ao pacifismo radical de Alain ${ }^{4}$. Em Toulouse, Canguilhem conhece o imigrante italiano antifascista Silvio Trentin e começa a se engajar no movimento de resistência ao Fascismo e ao Nazismo. Mas a ida para Toulouse não é importante somente do ponto de vista da "transformação política" de Canguilhem, é ainda nessa cidade e nesse mesmo momento que o futuro sucessor de Bachelard inicia seus estudos em Medicina, fato que seguramente explica seu olhar atento ao problema da vida, abordado pelo prisma das relações entre o normal e o patológico.

Em entrevista de 1995, Canguilhem confirma que o final dos anos 30 e início dos anos 40 são marcados por dois importantes acontecimentos que serão fundamentais para seu devir filosófico: a Resistência e a Medicina 5 . E se, por um lado, a partir desse momento o pensamento de Canguilhem mostra-se mais diversificado e heterogêneo, tal como sugere Limoges, por outro lado, o leitor do tomo IV de suas Obras Completas pode constatar que a relação com a Resistência, assim como com a Medicina, funciona como fio condutor que garante coerência e unidade à multiplicidade teórica

4 Cf. LIMOGES, C. "Introduction: Philosophie biologique, histoires des sciences et interventions philosophiques. Georges Canguilhem (1940 - 1965)”. In: Georges Canguilhem, Oeuvres Complètes, t. IV, p. 8; BRAUNSTEIN, J.- F. "Présentation: À la decouverte d'un "Canguilhem perdu". In: Georges Canguilhem, Oeuvres Complètes, t. I, p. 112; CAMMELLI, M. “Présentatio: Le fascisme et les paysant (1935)”. In: Georges Canguilhem, Oeuvres Complètes, t. I, Pp. 518-523.

5 Cf. BING, F., BRAUNSTEIN, J.- F. "Entretien avec Georges Canguilhem". In: BING, F., BRAUNSTEIN, J.- F, ROUDINESCO, É. (org.). Actualité de Georges Canguilhem. Le normal et le pathologique. Le Plessis-Robinson: Institut Synthélabo, 1998 , p. 129. 
e prática vivenciada por Canguilhem entre os anos de 1940 e 1965.

Assim como o tomo I, os textos do tomo IV são apresentados cronologicamente. O livro está divido em três partes, sendo que cada uma delas corresponde às diferentes funções profissionais que Canguilhem assume durante o período. A primeira parte refere-se aos anos de ensino na Faculdade de Letras de Estrasburgo (1940-1948); a segunda parte cobre o período de 7 anos em que assume o cargo de inspetor geral (1948-1955) e, por fim, a terceira parte compreende os 10 primeiros anos de ensino na Sorbonne assim como o período em que foi diretor do Institut d'histoire des sciences et des techniques (1955-1965).

É seguramente na primeira parte do livro que a temática vitalista é mais explícita, afinal é precisamente nesse período que o filósofo defende sua tese de medicina sobre o normal e o patológico. Nesse sentido, a maioria dos textos dessa fase não deixa de ser uma antecipação ou um prolongamento das discussões da tese de 43. E não é de pouco interesse ao leitor do Essai ter acesso a alguns trechos de um curso dado por Canguilhem entre 1942 e 1943 , intitulado Les normes et le normal, assim como a um comentário do terceiro capítulo de A evolução criadora, de Bergson, redigido para suas aulas de agrégation entre 1941 e 1942. E se a importância de Bergson para uma reflexão sobre o poder criador da vida fora já apontada por Canguilhem em 1938, em "Activité technique et création", o artigo "Notes sur la situation faite en France à la philosophie biologique", de 1947, volta a insistir que no interior da tradição da filosofia francesa, de Descartes a Sartre, passando por Alain e Brunschvicg, "a vida não é reconhecida como objeto metafísico próprio" ${ }^{\text {e }}$ que o mérito da reflexão bergsoniana fora justamente o de ter realizado uma "metafísica da vida".

Mas, os anos de inspeção geral tampouco deixam de interes-

6 CANGUILHEM, G. "Notes sur la situation faite en France à la philosophie biologique”. In: Oeuvres Completes, t. IV, p. 311. 
sar do ponto de vista da filosofia da biologia de Canguilhem. Em 1952, Canguilhem publica o que seria sua tese complementar de filosofia: "La connaissance de la vie". Trata-se de uma coletânea de textos escritos entre 1945 e 1951. E apesar desses textos não terem sido publicados no tomo IV das Obras Completas, o volume traz outros textos do período que enriquecem a compreensão do vitalismo do autor. É o caso do artigo de 1955 "Organisme et modèles mécaniques. Réflexions sur la biologie cartésienne" que, além de comentar o então recém-publicado livro de Guéroult, Descartes selon l'ordre des raisons, retoma a discussão da filosofia mecanicista de Descartes e de seus limites em tratar do tema da vida e da criação, esboçada em 1937, em "Descartes et la technique". Ainda na segunda parte do livro, destacamos Besoin et Tendances, de 1952, que consiste no primeiro volume da coleção “Textes et documents philosophiques", da Hachette, dirigida pelo próprio Canguilhem. A coleção é pensada para os alunos de filosofia do último ano do segundo grau. Os volumes são temáticos e reúnem uma série de pequenos textos e trechos sobre o assunto. A ideia, segundo Canguilhem, é a de que essas coletâneas "contenham textos e documentos capazes de fornecer rudimentos sólidos e conjuntos coerentes"7. E apesar da coletânea ser, a princípio, dirigida a iniciantes em filosofia ela não deixa de ser atraente aos mais iniciados. A escolha dos textos, pelo fato de implicar uma seleção, como ressalta o próprio organizador na apresentação da coleção, implica também certos princípios. Nesse sentido, aqueles que estudam a filosofia e a obra de Canguilhem certamente se sentirão instigados a compreender o princípio que esteve por trás das escolhas textuais do volume Besoin et Tendances, escolhas que vão da filosofia à literatura, da biologia à economia, passando ainda pela medicina e pela psicanálise.

7 CANGUiLHEM, G. "Présentations de la collection: Besoins et tendences". In: Oeuvres Completes, t. IV, p. 439. 
A terceira parte do tomo refere-se ao decênio $1955^{-1965}$ e, como dissemos, cobre os primeiros anos de ensino na Sorbonne e os de direção do Institut d'histoire des sciences et des techniques. Do ponto de vista dos acontecimentos históricos, não podemos deixar de lembrar que essa década é marcada pela Guerra de Argélia e que Canguilhem não deixou de se manifestar a favor da independência da colônia francesa e do fim da guerra. Em 1955, por exemplo, ao lado de outros intelectuais, assina a petição "Pour la paix en Algérie"; em 1958, publica dois artigos na revista "La Dépêche du Midi”, "De la République des Professeurs à la République des Colonels" e "Colonels et psychologie", denunciando a precariedade política e a fragilidade democrática na França, depois da Segunda Guerra Mundial. Insiste, dentre outras coisas, que os dirigentes da 4 a República e os "cabeças" do exército gabam-se por fundamentar suas estratégias políticas e militares em uma psicologia da massa baseada numa teoria do reflexo e da adaptação. Canguilhem ressalta, contudo, que a apropriação política desse tipo de psicologia é muito perigoso e lembra as técnicas comunistas e fascistas de dominação e de condicionamento da opinião pública.

Que Canguilhem tenha suas reservas em relação à psicologia de um Pavlov, por exemplo, não é de se estranhar. Suas reflexões no âmbito da filosofia da vida, da biologia ou da medicina, deixam entrever uma crítica ao behaviorismo na medida em que pensam a relação entre indivíduo e meio não de modo mecânico, mas dinâmico. A aposta do poder criador da vida vai nesse sentido. A vida não é simples adaptação ao meio; ela é também capaz de resistir e de transformar o meio. E aqui Medicina e Resistência voltam a se encontrar. Encontro que é evidente não somente nos anos em que o filósofo redige sua tese de medicina e participa ativamente do movimento de Resistência; em que escreve sobre Bergson, assim como homenageia a coragem política de Jean Cavaillès, membro ativo da Resistência. Também durante os anos de inspeção, a reflexão filosófica nunca deixou de ter um cunho po- 
lítico; seus pronunciamentos acerca do ensino da filosofia ressaltam sempre a capacidade humana de resistir, transformar e criar. Para Canguilhem, a filosofia tem papel libertador: "é nas aulas de filosofia que os alunos aprendem a liberdade pelo exercício da reflexão", assegura o filósofo em 1953, em documento escrito para a Unesco sobre o ensino de filosofia. E tenhamos claro que a tarefa libertadora da filosofia não está no fato de ela ser a portadora da verdade. Longe disso. "O valor de uma filosofia está além da verdade”, insiste Canguilhem em 1964, em entrevista ao jovem Alain Badiou. "Só há um domínio em que se pode falar de verdade, é aquele da ciência"s. A filosofia, porém, não é uma ciência. Mas que os filósofos não se alarmem! "A verdade não é o único valor ao qual o homem pode se consagrar"9. Estejamos tranquilos. Canguilhem nos ensina que a filosofia pode ter valor ético, moral, estético e, acima de tudo, político. Evidenciar isso é, pois, um dos maiores méritos de uma edição das Obras Completas do filósofo.

8 CANGUILHEM, G. "Philosophie et science". In: Oeuvres Completes, t. IV, p. 1106. 9 Ibid., p. 1107. 